\title{
GS/DBM/PLA porous composite biomaterial for the treatment of infective femoral condyle defect in rats
}

\author{
XIAOMING LIU ${ }^{1,2^{*}}$, LIN YANG $^{3 *}$, JING LI $^{2}$, YUMING ZHANG ${ }^{2}$, WEIJUN XU ${ }^{2}$, \\ YAN REN ${ }^{4}$, BIWANG LIU ${ }^{5}$, BIAO YANG ${ }^{2}$ and BAOXING LI ${ }^{1,2}$ \\ ${ }^{1}$ Department of Human Anatomy, Guangdong Provincial Key Laboratory of Medical Biomechanics, \\ Southern Medical University, Guangzhou, Guangdong 510515; ${ }^{2}$ China Institute for Radiation Protection, \\ Taiyuan, Shanxi 030006; ${ }^{3}$ Department of Human Anatomy, Zunyi Medical College, \\ Zhuhai, Guangdong 519041; ${ }^{4}$ Department of Medical Imaging, Shanxi Medical University; \\ ${ }^{5}$ Department of Traditional Chinese Medicine, Shanxi University, Taiyuan, Shanxi 030001, P.R. China
}

Received May 13,2015; Accepted November 25, 2015

DOI: $10.3892 /$ etm.2016.3219

\begin{abstract}
A bone defect resulting from open bone trauma may easily become infected; however, the administration of efficacious systemic antibiotics cannot be performed at safe levels. Previous studies have investigated anti-infective biomaterials that incorporate into bone and facilitate the direct application of high-concentration local antibiotics. In the present study, the effect of a novel porous composite with gentamicin sulfate (GS) in treating infected femoral condyle defects was investigated using a rat model. A novel porous composite biomaterial was prepared based on a supercritical carbon dioxide fluid technique that combined GS, demineralized bone matrix (DBM) and polylactic acid (PLA). A rat femoral condyle fracture model of infection was established. The GS/DBM/PLA composite biomaterial was implanted and its physicochemical characteristics, biocompatibility and ability to facilitate repair of infected bone defect were assessed. The GS/DBM/PLA composite biomaterial maintained the antibiotic activity of GS, with good anti-compression strength, porosity and biocompatibility. The results of the animal experiments indicated that the GS/DBM/PLA composite biomaterial exerted marked anti-infective effects and facilitated bone defect repair, while simultaneously controlling infection. Porous GS/DBM/PLA is therefore a promising composite biomaterial for use in bone tissue engineering.
\end{abstract}

Correspondence to: Dr Baoxing Li, China Institute for Radiation Protection, 102 Xuefu Street, Taiyuan, Shanxi 030006, P.R. China E-mail: pplxmpp@163.com

${ }^{*}$ Contributed equally

Key words: bone tissue engineering, infection, bone defect, composite biomaterial

\section{Introduction}

Bone grafting is performed on millions of patients suffering from bone trauma and bone defects caused by wars, traffic accidents, sports injuries, diseases and natural disasters. Bone grafting is the second most frequently performed type of tissue transplant following blood transfusion (1). In 1995, Crane et al (2) proposed the concept of using bone tissue engineering for the repair of bone defects. Since then, this technology has achieved marked progress, in fundamental research and clinical application in repairing bone defects $(3,4)$ and in total joint replacement $(5,6)$. There are three types of scaffold materials used in bone tissue engineering: Natural, artificially synthesized inorganic, and artificially synthesized polymers. Generally, a single type of scaffold material does not satisfy the current requirements for an extracellular scaffold, which are as follows: Enhanced mechanical strength, improved degradation time and increased biological activity. Therefore, numerous studies have investigated the use of two or more materials in the composition of scaffold materials (7-9). By selecting appropriate components and adjusting the proportion of each, composite materials with adjustable degradation characteristics and mechanical properties may be produced.

It has been widely recognized that, following autogenous bone, allograft bone is the best substitute material for bone grafting. Demineralized bone matrix (DBM), prepared for allograft cortical bone through grinding, washing and decalcification, is a natural sustained-release carrier of bone morphogenetic proteins with favorable bone induction, bone conduction and biocompatibility properties $(10,11)$. However, DBM has poor mechanical properties and is difficult to model (12). The most widely applied artificially synthesized polymer scaffold material is polylactic acid (PLA), which has useful mechanical properties and is easy to model, but has no biological activity and poor cellular affinity (13). Therefore, a composite of DBM and PLA together may exhibit advantages compared with either material alone.

With effective utilization of antibiotics, concurrent infection of bone defects are well controlled. However, the postoperative infection rate of bone defects caused by open 

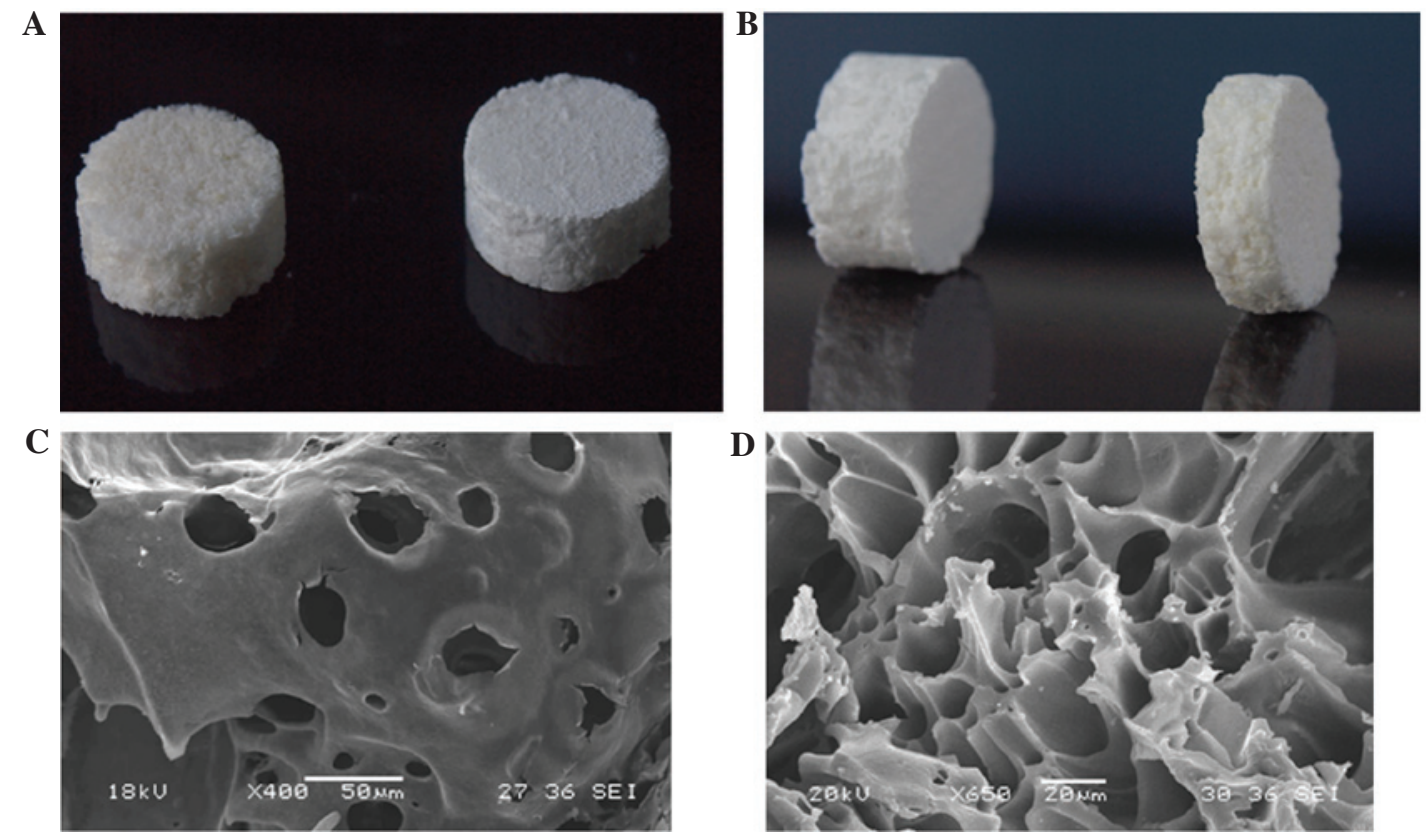

Figure 1: Images of GS/DBM/PLA composite biomaterial obtained using (A and B) optical microscopy and (C) scanning electron microscopy, identifying pores between 200-400 $\mu \mathrm{m}$ and (D) 20-30 $\mu \mathrm{m}$. GS, gentamicin sulfate; DBM, demineralized bone matrix; PLA, polylactic acid.

injuries remains as high as $20 \%$, even when debridement is conducted early in the procedure (14). The prevention and treatment of infected bone defects is more difficult compared with that of a simple bone defect (15). When a bone defect is infected, bone grafting in the first stage does not facilitate the union of the defect, but rather exacerbates the infection (16). Furthermore, single-dose administration of antibiotics at the site of bone grafting may not be effective, as systemic antibiotic administration cannot provide an effective concentration of antibiotics at the bone grafting site and can also have potential adverse side effects (17). One solution to this problem is to combine antibiotics with a scaffold material to prepare an anti-infective tissue-engineered bone material that is able to maintain a high local concentration of antibiotics at the bone grafting position, and a low concentration in the circulation. This may reduce the infection rate by increasing antibacterial activity locally at the bone grafting site (18).

With these considerations, the present study investigated the effect of a novel gentamicin sulfate (GS)/DBM/PLA porous composite for the treatment of an infected femoral condyle defect in a rat model.

\section{Materials and methods}

Preparation of DBM and PLA. The ethics committee of Shanxi Medical University (Taiyuan, China) approved the present study. Human cortical bones from numerous healthy and certified donors were ground and sifted to prepare bone powder with a diameter of 200-300 $\mu \mathrm{m}$. The bone powder was frozen, ultrasonically washed with distilled water for 3 days, decalcified in $0.6 \mathrm{~N} \mathrm{HCl}$ at $4^{\circ} \mathrm{C}$ for $48 \mathrm{~h}$ and lyophilized. A 1-g sample of $0.5 \times 10^{5}, 1 \times 10^{5}$ or $5 \times 10^{5}$ Da PLA (Daigang Biomaterial Co., Ltd., Jinan, China) was mixed with $2 \mathrm{~g} \mathrm{NaCl}$ (diameter, 200-300 $\mu \mathrm{m}$, determined by molecular sieve), at a PLA-to- $\mathrm{NaCl}$ ratio of 1:2. The mixed composition was put into a 10-ml supercritical cylinder reactor vessel linked to supercritical (SC)- $\mathrm{CO}_{2}$ reaction apparatus (SFE-2; Applied Separations, Inc., Allentown, PA, USA). The pressure of the container was gradually raised to $20 \mathrm{MPa}$ and the temperature was increased to $37^{\circ} \mathrm{C}$, and was maintained at $37 \pm 1^{\circ} \mathrm{C}$, with the pressure variation kept within $0.1 \mathrm{MPa}$ of this. After maintaining the temperature and pressure for $30 \mathrm{~min}$, they were decreased slowly over $15 \mathrm{~min}$ to room temperature and pressure. PLA samples were then removed from the vessel and leached with distilled water for $48 \mathrm{~h}$ to completely remove the $\mathrm{NaCl}$. Following lyophilization, the samples were packed in a three-layer aseptic package (Fuhua Medical Packing Co., Ltd., Nantong, China) and irradiated with $20 \mathrm{kGy}{ }^{60} \mathrm{Co}$ (China Nuclear Power Engineering Co., Ltd, Beijing, China) for sterilization.

Preparation of porous GS/DBM/PLA composite biomaterial. To produce the biomaterial, $0.6 \mathrm{~g}$ DBM (particle size, 200-300 $\mu \mathrm{m}$; Shanxi Provincial Tissue Bank, Taiyuan, China) and 0.4 g PLA (molecular weight, $1 \times 10^{5}$; Daigan Biological Materials, Jinan, China) were weighed at a DBM-to-PLA ratio of 3:2, in addition to $0.5 \mathrm{~g}$ GS powder (BBI Life Sciences Corporation, Shanghai, China) and $2 \mathrm{~g} \mathrm{NaCl}$ (diameter, 200-300 $\mu \mathrm{m}$ ). These materials were all white powders and were mixed thoroughly prior to being placed into the $10-\mathrm{ml}$ supercritical reactor vessel. The vessel was then linked to the supercritical $\mathrm{CO}_{2}$ reaction apparatus and the preparation proceeded as described for the DBM and PLA. Optical and scanning electron microscope (JSM-6360LVV; JEOL, Ltd., Tokyo, Japan) images of the composite biomaterial are presented in Fig. 1. GS/DBM/PLA was prepared to a ratio of 5:3:2.

Characteristics of the porous GS/DBM/PLA composite biomaterial. For the evaluation of the biomechanical properties of 


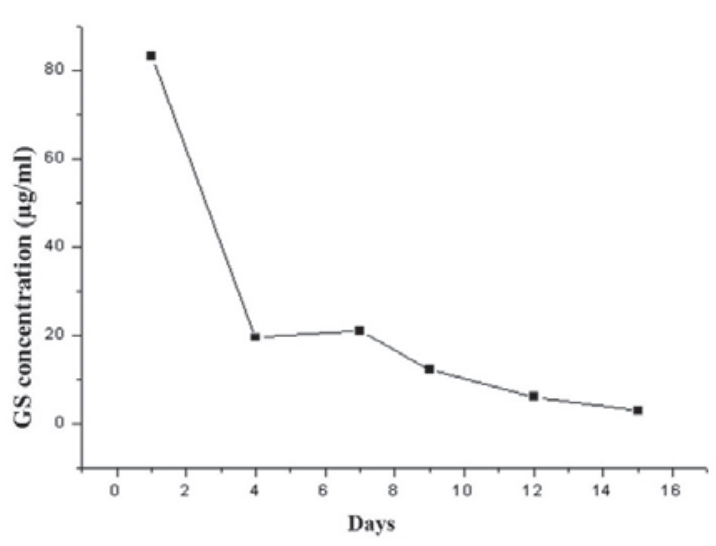

Figure 2. Release curve of GS/DBM/PLA in vitro.

the composite biomaterials, specific gravity was measured as an indication of porosity, and compressive strength and elastic modulus were determined using an RGT-20A microcomputer-controlled electronic universal testing machine (Shenzhen Reger Instrument Co. Ltd., Shenzhen, China). Cytotoxicity was detected in the mouse fibroblast cell line L-929 (Shanxi Provincial Tissue Bank) using an MTT assay. Briefly, mouse fibroblast cells at passage 3 were cultured together with extracts of GS/DBM/PLA and DBM/PLA in 96-well culture plates, with DMEM medium serving as a control. After culturing for 1, 2, 3, 4, 5, 6 and 7 days, MTT solution (Sigma-Aldrich, St. Louis, MO, USA) was added to each well and the cells were cultured for an additional $4 \mathrm{~h}$. Subsequent to this, $150 \mu \mathrm{l}$ DMSO was added to each well and the optical density was examined using a Model 680 microplate reader (Bio-Rad Laboratories, Inc., Hercules, CA, USA) at a wavelength of $570 \mathrm{~nm}$ to determine cell viability in the presence of these compounds. Next, the prepared GS/DBM/PLA composite was trimmed to uniform size $(10 \mathrm{x} 5 \mathrm{~mm})$. Fifteen test tubes were prepared and $10 \mathrm{ml}$ normal saline was added to each under sterile conditions. The prepared GS/DBM/PLA materials were put into test tube 1 , soaked for $4 \mathrm{~h}$ at $37^{\circ} \mathrm{C}$ and the next day removed to test tube 2 . Then, the process was repeated from tube 2 to tube 3 , successively up to tube 15 (day 15). During this time, the gentamicin in the GS/DBM/PLA composite gradually leached into the normal saline. A microbial inhibitory concentration test was then conducted on the saline in each of the tubes to determine the antibacterial concentration at different times and to produce an in vitro release curve of gentamicin (Fig. 2). Subsequent to this, prepared GS/DBM/PLA composite was trimmed to uniform size $(5 \times 5 \mathrm{~mm})$, and placed into the muscle of rats (described below). At postoperative days 1, 4, 7, 9, 12 and 15, $3 \mathrm{~mm}$ muscular tissue around the implanted materials was removed and $2 \mathrm{~mm}$ blood was collected from the abdominal aorta [using heparin anticoagulant (Sigma-Aldrich)]. The biological samples were stored in a cryogenic refrigerator (DW-25L92; Haier Group, Qindao, China) at $-20^{\circ} \mathrm{C}$. Then, under sterile conditions, the preserved muscle tissue and blood were homogenized in phosphate-buffered saline solution, centrifuged for $10 \mathrm{~min}$ at $37^{\circ} \mathrm{C}, 2,300 \mathrm{x} \mathrm{g}$, and the supernatant was collected. Microbial inhibitory concentration was detected in this saline by a golden Staphylococcus microbiological

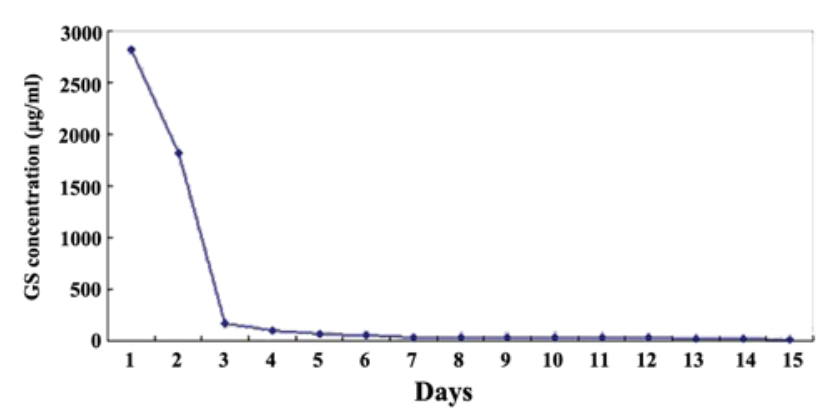

Figure 3. Release curve of GS/DBM/PLA in vivo.

test, based on flat colony counting methods (Shanxi Medical University), and an in vivo release curve was mapped (Fig. 3).

Preparation of the animal model. A total of 84 Wistar rats were used (Shanxi Medical University Medical Laboratory Animal Center). These were kept at $26^{\circ} \mathrm{C}$, in pathogen-free conditions with a 12-12 h light-dark cycle. The body weight of rats was $\sim 300 \mathrm{~g}$, and the sample included male and female rats. The requisite approval was obtained from the local ethics committee. The rats were divided into four groups, as follows: The control group, in which no experiment was conducted; the GS/DBM/PLA plus Staphylococcus aureus (SA) group; the DBM/PLA plus SA group; and the DBM/PLA without SA group, with 21 rats per group. The rats were anesthetized with $0.6 \%$ pentobarbital sodium (30 mg/100 g; Merck Millipore, Darmstadt, Germany) and fixed prostrate to the operating platform. Following depilation and sterilization around the femoral condyle, with drapes covering the skin, subcutaneous tissue and deep fascia were incised by layer. The muscles were bluntly dissected to prepare for a bilateral femoral condyle defect. A $1-\mathrm{cm}$ incision on the lateral femoral condyle was made to expose the lower end of the femur. The incision did not penetrate into the articular cavity in order to protect the articular cartilage (Fig. 4A). A dental ball drill (diameter, $1.6 \mathrm{~mm}$ ) was applied to drill in from the lateral side of the femoral condyle along the bone shaft axis (Fig. 4B), reaching the bone cortex on the opposite side but not damaging it. Then, the defect in the condyle was enlarged until it was $60-70 \%$ of the volume of the femoral condyle (Fig. 4C). The defect was washed with sterile saline and dried with a sterile gauze. Then, $10 \mu 1$ SA standard solution $\left(1 \times 10^{11} \mathrm{CFU} / \mathrm{ml}\right.$; Shanxi Medical University) was injected into the defect by pipette (Fig. 4D). After $30 \mathrm{~min}, ~ 80 \mathrm{mg} \mathrm{GS} / \mathrm{DBM} / \mathrm{PLA}$ or DBM/PLA was implanted into the defect. Following suturing, the incision was tightly covered, but the operated limb was not fastened. The rats were fed conventionally following the operation. Rats were sacrificed prior to the following experiments using an injected overdose of pentobarbital sodium $(40-60 \mathrm{mg} / 100 \mathrm{~g})$, at 4,6 or 8 weeks after the first operation.

Radiographic observation and bone density analysis. Three rats (six sites of femoral condyle defects) in each group were selected and anesthetized with $0.6 \%$ pentobarbital sodium $(30 \mathrm{mg} / 100 \mathrm{~g})$ at 4,6 and 8 weeks after the operation described above. To investigate new bone growth and reconstruction of bone, radiographs were captured using an SMX-1000 Plus X-ray inspection system (Shimadzu, Kyoto, Japan). The 

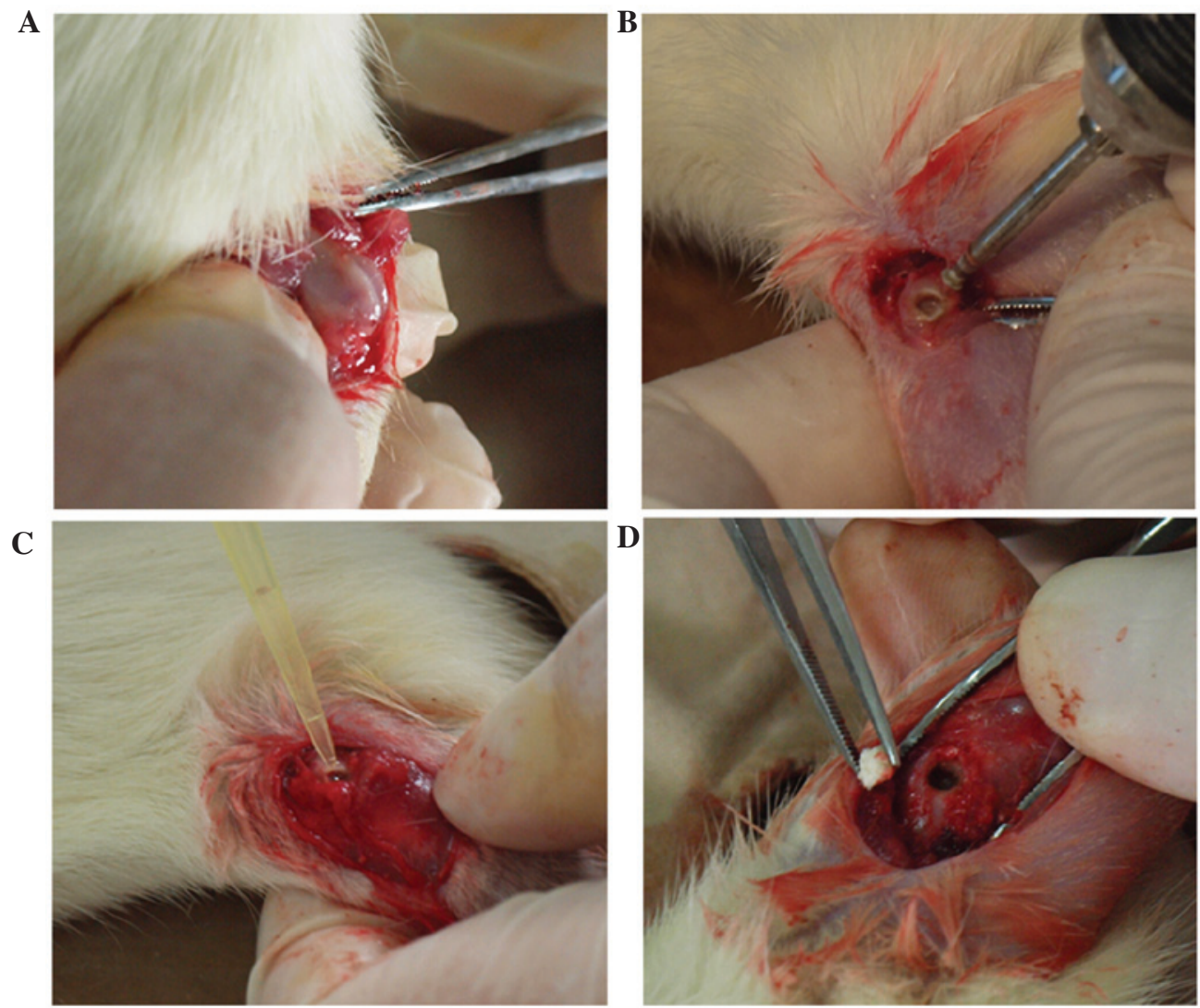

Figure 4. Infection modeling and composite biomaterial implants in a rat model with femoral condyle fracture deficiencies. Images show the (A) exposure of the femoral condyle fracture during surgery, (B) dental drill removing the deficiencies, (C) addition of Staphylococcus aureus solution to the wound and (D) implantation of the composite biomaterial.

grayscale value per unit area of defect was measured using image analysis software (Image-Pro Plus version 5.0; Media Cybernetics, Inc., Rockville, MD, USA) to evaluate the bone repair condition instead of bone mineral density.

Biomechanical compression tests. Four rats from each group were selected and the left femoral condyles were inspected at 4,6 , and 8 weeks after the operation. For comparison, the left femoral condyles of the Wistar rats in the control group with normal age and weight were inspected at the same position. The femoral condyles were fixed onto the biomechanics machine (WD-P4204; Jinan Test Machine Co., Ltd., Jinan, China) table and compressed at a rate of $5 \mathrm{~mm} / \mathrm{min}$. During the process, the femoral condyle displacement/time and displacement/load were determined. A displacement of $2 \mathrm{~mm}$ (femoral condyle thickness, $\sim 5 \mathrm{~mm}$ ) was defined as structural damage and this pressure (the breaking load) was used to evaluate the carrying capacity (compression area, $\sim 24 \mathrm{~mm}^{2}$ ).

Histological observation. Four rats from each group were selected and the right femoral condyles were inspected at 4, 6 and 8 weeks after the operation. The bone at the bilateral femoral condyle (weight, $\sim 2 \mathrm{~g}$ ) was excised until sterile conditions. The samples were then fixed in $10 \%$ neutral buffered formalin for $24 \mathrm{~h}$, decalcified in $50 \%$ formic acid, dehydrated in an $80-100 \%$ ethyl alcohol series, a $95-100 \%$ hyaline xylene series and prepared for paraffin embedding. The samples were sectioned longitudinally at $5 \mu \mathrm{m}$ and stained with hematoxylin and eosin (Sigma-Aldrich). The bone union in the grafted area was then observed under an optical microscope (IX73; Olympus Corporation, Tokyo, Japan).

Statistical analysis. Data analysis was performed using SPSS version 18.0 statistical software (SPSS, Inc., Chicago, IL, USA). Data are presented as the mean \pm standard deviation. The porosity was analyzed by rank correlation, and intergroup comparisons were carried out by one-way analysis of variance using the multi-sample average. If the homogeneity of variance was satisfied, the intergroup multiple comparisons were conducted with the method of least significance difference, and for heterogeneity, Tamhane's T2 post hoc test was applied to the intergroup multiple comparisons. Comparisons between two group were performed using the Student's t-test or t-test (for heterogeneity of variance) using the independent sample average. The optical density value measured by the cytotoxicity test was analyzed through factorial design variance analysis. $\mathrm{P}<0.05$ was considered to indicate a statistically significant difference.

\section{Results}

Physical and chemical properties of GS/DBM/PLA and $D B M / P L A$. The porosity of the composite biomaterials GS/DBM/PLA (5:3:2) and DBM/PLA (3:2) were evaluated using a t-test. The porosity of GS/DBM/PLA (77.08\%) was significantly reduced compared with DBM/PLA (79.71\%) 
Table I. Porosity of GS/DBM/PLA and DBM/PLA composite biomaterials $(n=5)$.

\begin{tabular}{lc}
\hline Composite material & Porosity (\%) \\
\hline GS/DBM/PLA & $77.08 \pm 1.63^{\mathrm{a}, \mathrm{b}}$ \\
DBM/PLA & $79.71 \pm 1.23^{\mathrm{a}, \mathrm{b}}$
\end{tabular}

${ }^{\mathrm{a}} \mathrm{t}=2.877 ;{ }^{\mathrm{b}} \mathrm{P}=0.021$. GS, gentamicin sulfate; DBM, demineralized bone matrix; PLA, polylactic acid.
Table II. Compressive strength and elastic modulus of GS/DBM/PLA and DBM/PLA composite biomaterials $(n=5)$.

Composite material Compressive strength Elastic modulus

\begin{tabular}{lll}
\hline GS/DBM/PLA & $100.99 \pm 7.28^{\mathrm{a}, \mathrm{b}}$ & $13.82 \pm 2.00^{\mathrm{c}, \mathrm{d}}$ \\
DBM/PLA & $108.71 \pm 4.19^{\mathrm{a}, \mathrm{b}}$ & $11.82 \pm 0.94^{\mathrm{c}, \mathrm{d}}$ \\
\hline
\end{tabular}

${ }^{\mathrm{a}} \mathrm{t}=2.056 ;{ }^{\mathrm{b}} \mathrm{P}=0.074 ;{ }^{\mathrm{c}} \mathrm{t}=2.028 ;{ }^{\mathrm{d}} \mathrm{P}=0.077$. GS, gentamicin sulfate; DBM, demineralized bone matrix; PLA, polylactic acid.

Table III. OD values for the proliferation of mouse fibroblast L929 cells in the presence of composite biomaterials ( $\mathrm{n}=5$ ).

\begin{tabular}{|c|c|c|c|c|c|c|}
\hline \multirow[b]{2}{*}{ Day } & \multicolumn{3}{|c|}{ Composite biomaterial } & \multirow[b]{2}{*}{ Mean OD } & \multirow[b]{2}{*}{ F-value } & \multirow[b]{2}{*}{ P-value } \\
\hline & Control & DBM/PLA & GS/DBM/PLA & & & \\
\hline 1 & $0.392 \pm 0.040$ & $0.515 \pm 0.022$ & $0.395 \pm 0.051$ & $0.434 \pm 0.070$ & 15.618 & $<0.001$ \\
\hline 2 & $0.474 \pm 0.060$ & $0.577 \pm 0.027$ & $0.457 \pm 0.044$ & $0.503 \pm 0.069$ & 10.152 & 0.003 \\
\hline 3 & $0.582 \pm 0.019$ & $0.546 \pm 0.044$ & $0.584 \pm 0.019$ & $0.570 \pm 0.033$ & 2.616 & 0.114 \\
\hline 4 & $0.716 \pm 0.081$ & $0.744 \pm 0.047$ & $0.702 \pm 0.040$ & $0.721 \pm 0.057$ & 0.651 & 0.539 \\
\hline 5 & $1.306 \pm 0.053$ & $1.272 \pm 0.043$ & $1.282 \pm 0.066$ & $1.287 \pm 0.053$ & 0.504 & 0.616 \\
\hline 6 & $1.388 \pm 0.045$ & $1.346 \pm 0.029$ & $1.392 \pm 0.037$ & $1.375 \pm 0.041$ & 2.328 & 0.140 \\
\hline 7 & $1.325 \pm 0.027$ & $1.304 \pm 0.036$ & $1.316 \pm 0.035$ & $1.315 \pm 0.032$ & 0.478 & 0.632 \\
\hline Mean & $0.883 \pm 0.415^{\mathrm{a}, \mathrm{b}}$ & $0.901 \pm 0.366^{\mathrm{a}, \mathrm{b}}$ & $0.876 \pm 0.413^{\mathrm{a}, \mathrm{b}}$ & $0.886 \pm 0.394$ & 4.318 & $<0.001$ \\
\hline $\mathrm{F}$ & 380.161 & 562.808 & 498.743 & 1376.194 & - & - \\
\hline
\end{tabular}

${ }^{\mathrm{a}} \mathrm{F}=2.983 ;{ }^{\mathrm{b}} \mathrm{F}=4.318$. The F-value column represents the difference between the three groups, whereas the $\mathrm{F}$ row represents the difference in a single group over the 7-day period. OD, optical density; GS, gentamicin sulfate; DBM, demineralized bone matrix; PLA, polylactic acid.

Table IV. Cell toxicity of GS/DBM/PLA and DBM/PLA leachates.

\begin{tabular}{llllllll}
\hline & \multicolumn{7}{c}{ Day } \\
\cline { 2 - 7 } Group & 1 & 2 & 3 & 4 & 5 & 6 & 7 \\
\hline GS/DBM/PLA & 0 & 1 & 0 & 1 & 1 & 0 & 1 \\
DBM/PLA $^{\mathrm{a}}$ & 0 & 0 & 1 & 0 & 1 & 1 & 1 \\
\hline
\end{tabular}

3:2. GS, gentamicin sulfate; DBM, demineralized bone matrix; PLA, polylactic acid.

$(\mathrm{t}=2.877 ; \mathrm{P}=0.021 ;$ Table $\mathrm{I})$. The compressive strength and elastic modulus of the GS/DBM/PLA and DBM/PLA materials were evaluated using a t-test (Table II). The t-values were 2.056 and 2.028, and the P-values were 0.074 and 0.077 , respectively. Thus, there was no significant difference between the two groups with regards to compressive strength or elastic modulus, although the compressive strength and elastic modulus of GS/DBM/PLA was slightly inferior to that of DBM/PLA. Table III presents the data demonstrating the effects of GS/DBM/PLA and DBM/PLA composite gentamicin leachate on cellular proliferation and Table IV presents the cytotoxicity rating of GS/DBM/PLA and DBM/PLA composites. There are significant differences in the cell optical density values at different time points $(\mathrm{F}=1376.194 ; \mathrm{P}<0.001)$, and the difference is also significant between GS/DBM/PLA and DBM/PLA $(\mathrm{F}=2.983 ; \mathrm{P}<0.001)$. From days 3 to 7 , there is no statistical difference among the control, DBM/PLA and GS/DBM/PLA groups. The relative rate of cellular proliferation from days 3 to 7 was $>90 \%$ following treatment with GS/DBM/PLA composite leachate and the cell toxicity rating was 0 or 1 , indicating that the GS/DBM/PLA composite was almost non-cytotoxic relative to the DBM/PLA composite material.

$X$-ray observation. Representative X-rays of the three different groups are presented in Fig. 5. In the GS/DBM/PLA group containing SA, at 4 weeks following implantation, the defect repair area appeared cloudy, and the density of this was highest at the center of the repair area (Fig. 5A). At 6 weeks after implantation, the flocculent resistance projection grew denser (Fig. 5A). At 8 weeks following implantation, the resistance projection at the defect region was nearly as dense as normal bone (Fig. 5A). In the DBM/PLA group containing SA, at 4 weeks following implantation there was clear and uniform flocculent resistance projection in the defect repair area and the defect center was radiolucent (Fig. 5B). At 6 weeks following implantation, the flocculent resistance projection grew denser and more uniform, but there remained a large 
A

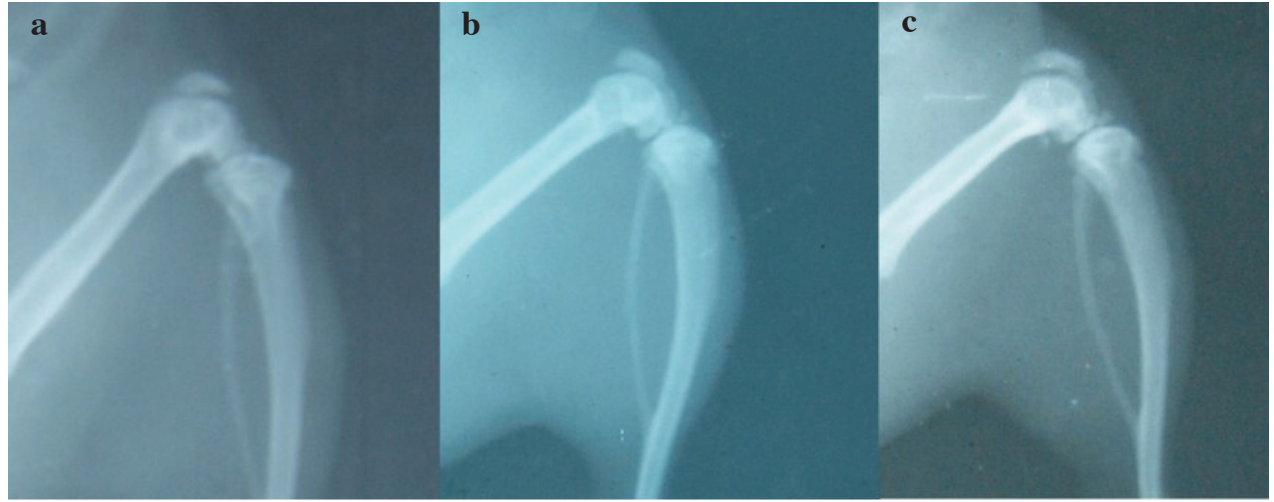

B

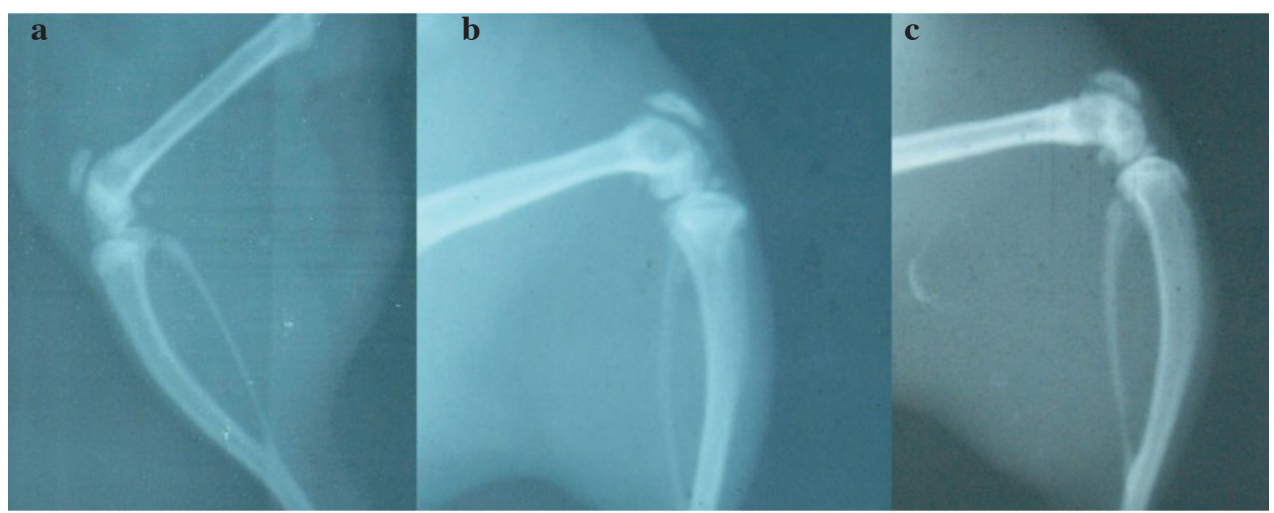

C

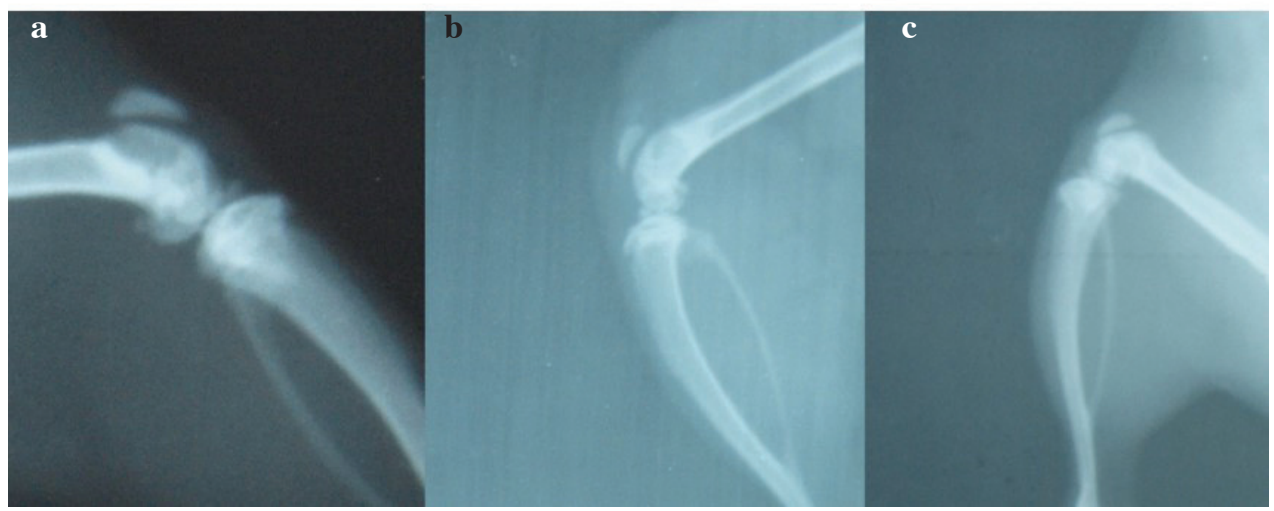

Figure 5. X-ray radiographs of the implanted biomaterial for the (A) non-operated control, (B) GS/DBM/PLA and (C) DBM/PLA group. (a) 4 weeks, (b) 6 weeks and (C) 8 weeks after surgery. GS, gentamicin sulfate; DBM, demineralized bone matrix; PLA, polylactic acid.

area of transparent zones that could be observed in the defect area (Fig. 5B). At 8 weeks following implantation, the flocculent resistance projection was more dense and the transparent zones in the center of the defect were smaller and irregular (Fig. 5C). In the DBM/PLA group without SA, at 4 weeks following implantation, there was flocculent resistance projection in the defect repair area and the transparent zones in the center of defect were not obvious (Fig. 5A). At 6 weeks following implantation, the flocculent resistance projection was uniform and dense (Fig. 5B). At 8 weeks following implantation, the defect region was nearly as dense as normal bone (Fig. 5C).

Analysis of bone density measurement. Variance analysis was conducted to evaluate the gray values (bone mineral density) of materials collected at 4, 6 and 8 weeks post-operation, and there was significant difference recorded at each point (Table V). At 4 weeks, $\mathrm{F}=56.248, \mathrm{P}<0.001$; at 6 weeks,
$\mathrm{F}=57.704, \mathrm{P}<0.001$; and at 8 weeks, $\mathrm{F}=25.793, \mathrm{P}<0.001$. Further intergroup comparisons demonstrated statistical differences between each pair of groups $(\mathrm{P}<0.001)$. The grey value of the DBM/PLA group without SA was highest, and that of the DBM/PLA group containing SA was the lowest. In addition, the grey value of the GS/DBM/PLA group containing SA was significantly higher compared with the DBM/PLA group containing SA. These results suggest that the DBM/PLA material could promote the repair of bone defects and that GS/DBM/PLA was beneficial to bone defect repair as a result of its ability to reduce local infection.

Biomechanical compression tests. Variance analysis was conducted to evaluate the breaking load and breaking strength of composite materials at 6 and 8 weeks following operation, and there was significant difference between these values (Table VI). At 6 weeks, $\mathrm{F}=50.381, \mathrm{P}<0.001$, and at 8 weeks, $\mathrm{F}=93.291, \mathrm{P}<0.001$. Further intergroup comparison 
Table V. Bone mineral density (pixels; gray value) of bone repair in the area surrounding the composite material ( $\mathrm{n}=6)$.

\begin{tabular}{llcl}
\hline & \multicolumn{2}{c}{ Gray value (pixels) } \\
\cline { 2 - 4 } Composite material & Week 4 & Week 6 & Week $^{\mathrm{b}}$ \\
\hline Non-operated control & $2.223 \pm 0.328$ & $2.505 \pm 0.574$ & $3.993 \pm 0.597$ \\
GS/DBM/PLA & $1.230 \pm 0.265^{\mathrm{d}}$ & $1.693 \pm 0.296^{\mathrm{d}}$ & $2.850 \pm 0.555^{\mathrm{d}}$ \\
DBM/PLA & $3.333 \pm 0.420^{\mathrm{d}, \mathrm{e}}$ & $4.520 \pm 0.494^{\mathrm{d}, \mathrm{e}}$ & $5.968 \pm 1.035^{\mathrm{d}, \mathrm{e}}$ \\
\hline
\end{tabular}

${ }^{\mathrm{a}} \mathrm{F}$-value, 56.248; ${ }^{\mathrm{b}} \mathrm{F}$-value, 57.704; ${ }^{\mathrm{c}} \mathrm{F}$-value, $25.793 ;{ }^{\mathrm{d}} \mathrm{P}<0.05$ vs. non-operated control group; ${ }^{\mathrm{e}} \mathrm{P}<0.01$ vs. GS/DBM/PLA. GS, gentamicin sulfate; DBM, demineralized bone matrix; PLA, polylactic acid.

Table VI. Anti-compression biomechanical evaluation of the femoral condyle in the presence of a composite material with, or without, $\mathrm{SA}(\mathrm{n}=4)$.

\begin{tabular}{|c|c|c|c|c|}
\hline \multirow[b]{2}{*}{ Composite material } & \multicolumn{2}{|c|}{ Week $6^{\mathrm{a}}$} & \multicolumn{2}{|c|}{ Week $8^{\mathrm{b}}$} \\
\hline & Load $(\mathrm{N})$ & Strength (MPa) & Load $(\mathrm{N})$ & Strength $(\mathrm{MPa})$ \\
\hline GS/DBM/PLA (with SA) & $288.284 \pm 31.255$ & $12.012 \pm 1.302$ & $363.029 \pm 23.828$ & $15.126 \pm 0.993$ \\
\hline DBM/PLA (with SA) & $192.376 \pm 15.811^{\mathrm{c}}$ & $8.01 \pm 0.659^{c}$ & $248.687 \pm 21.465^{\mathrm{c}}$ & $10.362 \pm 0.894^{c}$ \\
\hline DBM/PLA (without SA) & $322.530 \pm 32.802^{\mathrm{d}}$ & $13.439 \pm 1.367^{\mathrm{d}}$ & $412.902 \pm 11.748^{\mathrm{a}, \mathrm{d}}$ & $17.204 \pm 0.490^{\mathrm{c}, \mathrm{d}}$ \\
\hline Normal control group & $88.696 \pm 22.174^{\mathrm{c}-\mathrm{e}}$ & $17.651 \pm 1.012^{\mathrm{c}-\mathrm{e}}$ & $527.878 \pm 33.655^{\mathrm{c}-\mathrm{e}}$ & $21.995 \pm 1.402^{\mathrm{c}-\mathrm{e}}$ \\
\hline
\end{tabular}

${ }^{\mathrm{a}} \mathrm{F}$-value, 50.381; ${ }^{\mathrm{b}} \mathrm{F}$-value, 93.291 ; ${ }^{\mathrm{c}} \mathrm{P}<0.05$ vs. non-operated control group; ${ }^{\mathrm{d}} \mathrm{P}<0.05$ vs. GS/DBM/PLA; ${ }^{\mathrm{e}}<0.05$ vs. DBM/PLA. GS, gentamicin sulfate; DBM, demineralized bone matrix; PLA, polylactic acid.

demonstrated that, except for the GS/DBM/PLA group containing SA and the DBM/PLA group without SA at 6 weeks $(\mathrm{P}=0.097)$, there was statistical difference among the other groups $(\mathrm{P}<0.05)$. The analysis indicated that the breaking load and breaking strength were highest in the normal control group, followed by the DBM/PLA group without SA, and that the breaking load and breaking strength were lowest in the DBM/PLA group containing SA, which was lower than those in the GS/DBM/PLA group containing SA. These differences were statistically significant and suggest that the DBM/PLA material can promote the repair of bone defects and that GS/DBM/PLA supported bone defect repair applying its anti-infection properties.

Histological observation. In the GS/DBM/PLA group containing SA, after 4 weeks, a small area of inflammatory tissue was observed among the implanted biomaterial (Fig. 6). After 6 weeks, mesenchymal cells grew into the implanted bone, and a number of inflammatory cells and polykaryocytes were also observed. Osteoblasts could be seen around the implanted material. After 8 weeks, the implanted area was completely substituted by new bone tissue and the condition of bone union was similar to that of the DBM/PLA group without $\mathrm{SA}$ at 8 weeks. In the DBM/PLA group containing SA after 4 weeks, the implanted material was covered by inflammatory fibrous tissue in which a large amount of inflammatory cells were observed. After 8 weeks, the implanted material was almost absorbed by the inflammatory fibrous tissue, despite some DBM fragments, and the implanted area was saturated with inflammatory fibrous tissue.

\section{Discussion}

In the present study, the GS/DBM/PLA porous composite was prepared using a $\mathrm{SC}-\mathrm{CO}_{2}$ fluid technique, and DBM/PLA was the sustained-release carrier for GS. It was observed that the porous GS/DBM/PLA composite material accelerated repair of bone defects while controlling infection in the rat model.

Poly(methyl methacrylate) (PMMA) was the earliest sustained-release drug material applied in clinical practice, and it achieves evident curative effect in the treatment of bone infections and bone defect repairs. However, PMMA has a number of limitations, including poor histocompatibility, heat release during polymerization, toxicity of its monomer, a second operation required to remove it and inadequate drug release (19). These disadvantages of PMMA impose many restrictions on its clinical application $(20,21)$.

A number of studies have been conducted on the materials that can provide sustained-release of antibiotics. For anti-infective bone defect repair, studies have investigated composites to contain antibiotics including allogeneic bone $(22,23)$, alginates (24), hydroxyapatites (25) and beta tricalcium phosphate (26). However, appropriate biological activity, degradability and mechanical strength cannot be satisfied by a single material, and therefore creating an anti-infective material that contains two different methods of producing sustained-release of antibiotic with desirable properties is a vital area of research. The DBM/PLA material prepared in the present study was demonstrated to have favorable biocompatibility, bone inductive activity and mechanical properties. When composited with GS, it exhibited good 
A

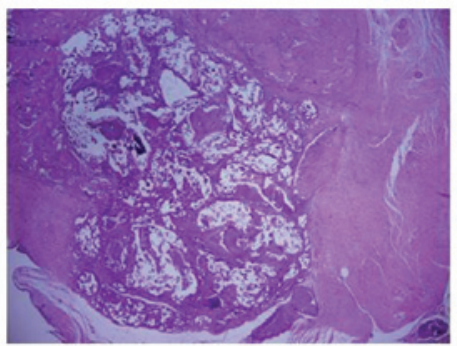

B

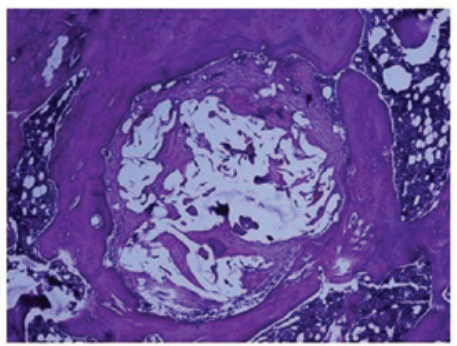

C

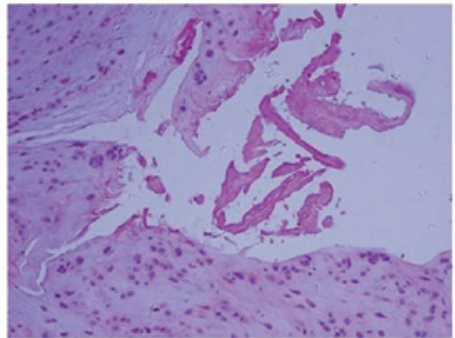

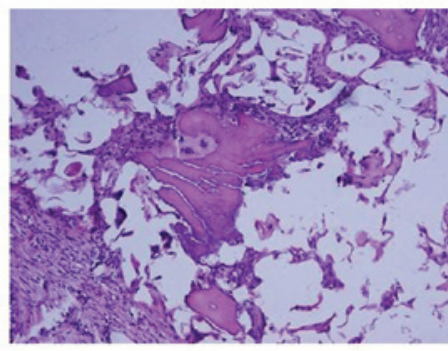
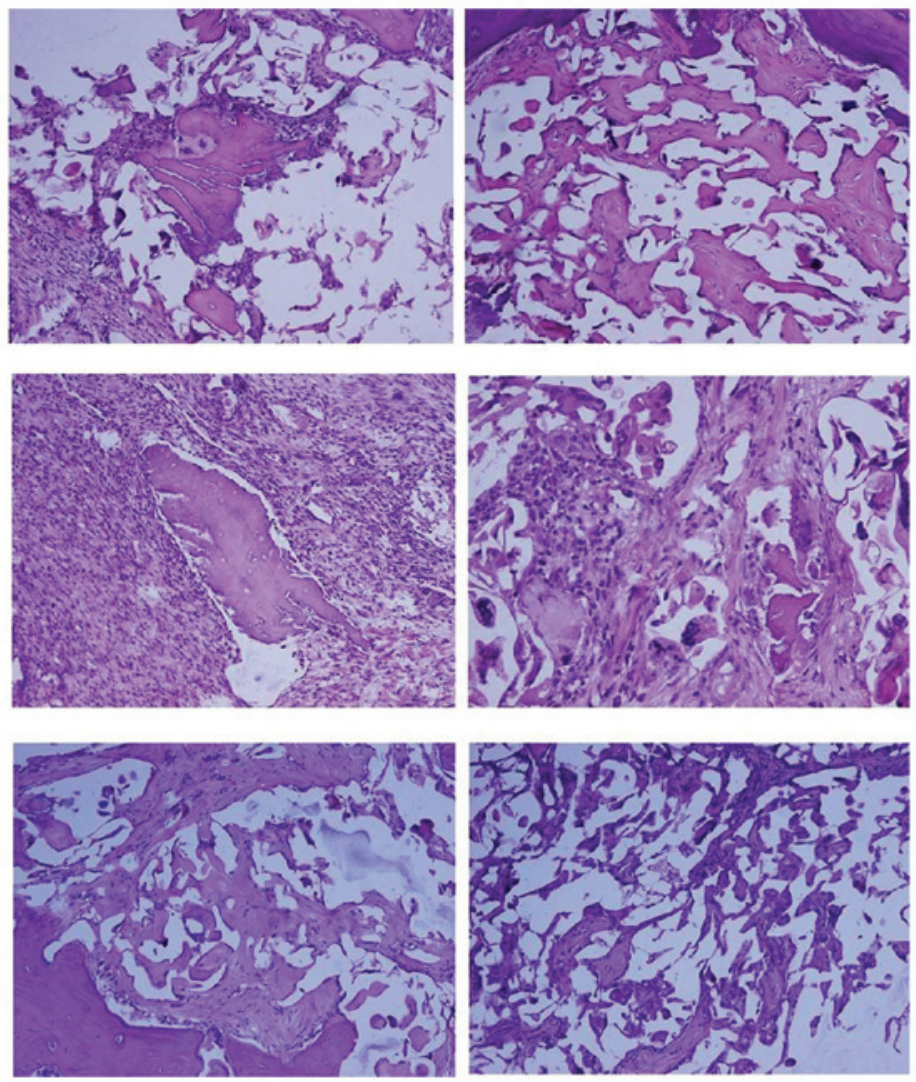

Figure 6. Histological images, stained with hematoxylin and eosin, of biomaterial implanting (A) after 4 weeks, displaying a small area of inflammatory tissue among the implanted biomaterial, (B) after 6 weeks, displaying mesenchymal cells growing into the implanted bone with a number of inflammatory cells, multinucleated cells around the demineralized bone matrix and osteoblasts in the lacuna, and (C) after 8 weeks, when the implanting area was fully covered with new-borne bone tissue, showing complete dissipation of inflammation (magnification, x100).

anti-infective ability, effectively inhibiting the growth of SA and promoting the union of bone defects.

After grafting, degradable material may fill the cavity of the bone defect and release a high concentration of antibiotics. Compared with systemic administration, this method avoids adverse antibiotic side effects as well as bacterial drug resistance (27). In addition, degradable material does not require a second operation to remove it; space for bone growth is provided as the material degrades (28). The degradable sustained-release materials PLA, polyglycolic acid and their copolymer poly(glycolide-co-lactide) have numerous advantages, including high local drug concentration, long maintenance time, lack of toxic and allergic reactions and acceptable compatibility with most antibiotics $(29,30)$. In addition, these materials can usually be metabolized in the human body and their decomposition products, carbon dioxide and water, have no toxic or other adverse side effects in humans (31).

The GS/DBM/PLA porous composite prepared in the current study combined the advantages of its three components: The easy modelling and good biomechanical properties of PLA, the biocompatibility and bone induction properties of DBM and the broad-spectrum antibacterial activity of GS. As a result, the composite has the favorable properties required to treat infected bone defects. As previously reported, when the porosity of a biomaterial is $>60 \%$, new bone tissue can grow from the surface inwards along the intercommunicated pores, forming a network structure (32). The porosity of the
GS/DBM/PLA porous composite in the present study was $77.1 \%$, and its compressive strength and elasticity modulus were $101.0 \pm 7.3$ and $13.8 \pm 2.0 \mathrm{MPa}$, respectively. Cell compatibility is another important indicator affecting bone tissue engineering material. The cytotoxicity grade of the GS/DBM/PLA porous composite in this study was rated as 0 or 1 , which is almost nontoxic. This satisfies the essential requirements for bone tissue engineering scaffold material.

In the present study, the materials were processed at $<37^{\circ} \mathrm{C}$ to ensure bioactivity during compositing. During the $\mathrm{SC}-\mathrm{CO}_{2}$ reaction process, low pressure may lead to oversized and uneven pores, while excessive pressure may cause complete swelling of the material and collapse of the pores (33). The reaction pressure in the present study was $20 \mathrm{MPa}$ and ideal porosity was obtained; the porosity of the DBM/PLA composite was $>65 \%$ and increased with the proportion of DBM, reaching $79.7 \%$ at the optimal composite proportion of DBM/PLA $(3: 2)$. High porosity enlarges the contact area between the scaffold material and cells, thus promoting the cell adhesive growth and facilitating the entrance of oxygen and nutrients, and the excretion of metabolic products.

Response time is another crucial factor that influences the size of pores in PLA material. The porosity of the material formed from pure PLA after $30 \mathrm{~min}$ of $\mathrm{SC}-\mathrm{CO}_{2}$ reaction is relatively high and the pore size is $\sim 300 \mu \mathrm{m}$; a reaction that is much shorter or longer is not beneficial to the formation of pores on the PLA surface (34). If the reaction time is too short the segmental motion will be incomplete, and if the reaction 
time is too long the chain segments will rearrange and there will be fewer pores. Adequate infiltration time ensures that carbon dioxide will infiltrate the sample sufficiently, and after pressure reduction and foaming, a porous scaffold material with high porosity will be obtained $(35,36)$. Therefore, in the present study the reaction time was set to $30 \mathrm{~min}$.

The pressure reduction time also has a marked influence on the porosity of the composite material. If the pressure reduction time is too short, the PLA will rapidly separate from the supercritical system and the curing speed will be high. Furthermore, the speed of $\mathrm{CO}_{2}$ overflowing out of the PLA will be high, leading to a low expansion rate (37). If the pressure reduction time is prolonged to $15 \mathrm{~min}$, the curing speed of the PLA and the overflow speed of the carbon dioxide will reduce, leaving sufficient time for a uniform foam to form and solidify, resulting in a microporous structure of relatively large diameter (38). On this basis, the current study adopted 15 min as the pressure reduction time.

Bucholz (39) proposed that the pore diameter of bone substitute material should not be $<100 \mu \mathrm{m}$, in order to avoid stunting the growth of bone. However, if the pore diameter is $>500 \mu \mathrm{m}$, the strength and cell adhesion rate of the material would be adversely affected. Porter et al (40) considered that a pore diameter of $>200 \mu \mathrm{m}$ is essential for bone conduction, and a pore diameter between 200 and $400 \mu \mathrm{m}$ is ideal for bone growth. Therefore, the pore diameter of the DBM/PLA porous composite prepared in the present study was between 200 and $400 \mu \mathrm{m}$. Thus, the material was able to promote the growth of bone tissue into the material and facilitate cell adhesion and nutrient diffusion. In addition, there were small pores (diameter, $20-30 \mu \mathrm{m}$ ) on the pore wall of the material which may assist the growth of bone tissue and blood vessels.

In conclusion, the GS/DBM/PLA porous composite prepared by the $\mathrm{SC}-\mathrm{CO}_{2}$ fluid technique has favorable porosity, mechanical properties, bone induction/conduction ability, local antibacterial ability and bone defect repair efficacy. Therefore, the GS/DBM/PLA porous composite is a potentially viable bone tissue engineering material for the repair of infective bone defects.

\section{Acknowledgments}

The present study was supported by a grant from the Shenzhen Governmental Basic Research Grant (no. JCYJ20120617115010496), the State Key Laboratory of Bioelectronics of Southeast University (Nanjing, China) and the Doctor Startup Foundation of Zunyi Medical College (no. F-746).

\section{References}

1. Roberts TT and Rosenbaum AJ: Bone grafts, bone substitutes and orthobiologics: The bridge between basic science and clinical advancements in fracture healing. Organogenesis 8: 114-124, 2012.

2. Crane GM, Ishaug SL and Mikos AG: Bone tissue engineering. Nat Med 1: 1322-1324, 1995.

3. Won YH, Kim SG, Oh JS and Lim SC: Clinical evaluation of demineralized bone allograft for sinus lifts in humans: A clinical and histologic study. Implant Dent 20: 460-464, 2011.

4. Lima CE, Calixto JC and Anbinder AL: Influence of the association between simvastatin and demineralized bovine bone matrix on bone repair in rats. Braz Oral Res 25: 42-48, 2011.
5. Zhang HY, Luo JB, Zhou M, Zhang Y and Huang YL: Biotribological properties at the stem-cement interface lubricated with different media. J Mech Behav Biomed Mater 20: 209-216, 2013.

6. Zhang H, Zhang S, Luo J, Liu Y, Qian S, Liang F and Huang Y: Investigation of protein adsorption mechanism and biotribological properties at simulated stem-cement interface. J Tribol 135: 032301, 2013.

7. Liu H, Zhang L, Shi P, Zou Q, Zuo Y and Li Y: Hydroxyapatite/polyurethane scaffold incorporated with drug-loaded ethyl cellulose microspheres for bone regeneration. J Biomed Mater Res B Appl Biomater 95: 36-46, 2010.

8. Xu C, Su P, Wang Y, Chen X, Meng Y, Liu C, Yu X, Yang X, $\mathrm{Yu}$ W, Zhang X, et al: A novel biomimetic composite scaffold hybridized with mesenchymal stem cells in repair of rat bone defects models. J Biomed Mater Res A 95: 495-503, 2010.

9. Thomas DB, Brooks DE, Bice TG, DeJong ES, Lonergan KT and Wenke JC: Tobramycin-impregnated calcium sulfate prevents infection in contaminated wounds. Clin Orthop Relat Res 441: 366-371, 2005.

10. Agarwal A, Goyal RK and Pruthi KK: Fate of calcium hydroxyapatite blocks with cortico-cancellous autogenous bone grafting in gap non-union of long bones along with LCP. J Clin Orthop Trauma 6: 72-73, 2015.

11. Ajiboye RM, Hamamoto JT, Eckardt MA and Wang JC: Clinical and radiographic outcomes of concentrated bone marrow aspirate with allograft and demineralized bone matrix for posterolateral and interbody lumbar fusion in elderly patients. Eur Spine J 24: 2567-2572, 2015.

12. Tavakol S, Khoshzaban A, Azami M, Kashani IR, Tavakol H, Yazdanifar M and Sorkhabadi SM: The effect of carrier type on bone regeneration of demineralized bone matrix in vivo. J Craniofac Surg 24: 2135-2140, 2013.

13. Turner TM, Urban RM, Hall DJ, Chye PC, Segreti J and Gitelis S: Local and systemic levels of tobramycin delivered from calcium sulfate bone graft substitute pellets. Clin Orthop Relat Res 437: 97-104, 2005.

14. Bakhshalian N, Hooshmand S, Campbell SC, Kim JS Brummel-Smith $\mathrm{K}$ and Arjmandi $\mathrm{BH}$ : Biocompatibility and microstructural analysis of osteopromotive property of allogenic demineralized dentin matrix. Int J Oral Maxillofac Implants 28: 1655-1662, 2013.

15. Jimi E, Hirata S, Osawa K, Terashita M, Kitamura C and Fukushima H: The current and future therapies of bone regeneration to repair bone defects. Int J Dentistry: 148261, 2012.

16. Chen ZW, Liu H, Zhai WL and Zhai WL: Treatment of infected bone defect with one stage open cancellous bone grafting. Zhongguo Gu Shang 21: 377-378, 2008 (In Chinese).

17. García-Gareta E, Coathup MJ and Blunn GW: Osteoinduction of bone grafting materials for bone repair and regeneration. Bone 81: 112-121, 2015.

18. Li XD and Hu YY: The treatment of osteomyelitis with gentamicin-reconstituted bone xenograft-composite. J Bone Joint Surg Br 83: 1063-1068, 2001.

19. Hautamäki MP, Aho AJ, Alander P, Rekola J, Gunn J, Strandberg N and Vallittu PK: Repair of bone segment defects with surface porous fiber-reinforced polymethyl methacrylate (PMMA) composite prosthesis: Histomorphometric incorporation model and characterization by SEM. Acta Orthop 79: 555-564, 2008

20. Zheng J, Su Q, Wang C, Cheng G, Zhu R, Shi J and Yao K: Synthesis and biological evaluation of PMMA/MMT nanocomposite as denture base material. J Mater Sci Mater Med 22: 1063-1071, 2011.

21. Li Z, Kawamura K, Kawashita M, Kudo TA, Kanetaka H and HiraokaM:Invitro assessment of poly(methylmethacrylate)-based bone cement containing magnetite nanoparticles for hyperthermia treatment of bone tumor. J Biomed Mater Res A 100: 2537-2545, 2012

22. Fong N, Poole-Warren LA and Simmons A: Development of sustained-release antibacterial urinary biomaterials through using an antimicrobial as an organic modifier in polyurethane nanocomposites. J Biomed Mater Res B Appl Biomater 101: 310-319, 2013.

23. Quaglino P, Nardò T, Fierro MT, Massaia M, Orsucci L, Fava P, Marenco F, Marra E, Savoia P, Vitolo U, et al: Clinicopathologic spectrum of cutaneous diseases in patients with hematologic malignancies with or without allogeneic bone marrow transplantation: An observational cohort study in 101 patients. G Ital Dermatol Venereol 148: 453-463, 2013. 
24. Anal AK and Stevens WF: Chitosan-alginate multilayer beads for controlled release of ampicillin. Int J Pharm 290: 45-54, 2005.

25. Buranapanitkit B, Srinilta V, Ingviga N, Oungbho K, Geater A and Ovatlarnporn C: The efficacy of a hydroxyapatite composite as a biodegradable antibiotic delivery system. Clin Orthop Relat Res 424: 244-252, 2004.

26. Silverman LD, Lukashova L, Herman OT, Lane JM and Boskey AL: Release of gentamicin from a tricalcium phosphate bone implant. J Orthop Res 25: 23-29, 2007.

27. Pandey M, Amin M, Ahmad N and Abeer MM: Rapid synthesis of superabsorbent smart-swelling bacterial cellulose/acrylamide-based hydrogels for drug delivery. Int J Polym Sci: 905471, 2013

28. Corden TJ, Jones IA, Rudd CD, Christian P, Downes S and McDougall KE: Physical and biocompatibility properties of poly-epsilon-caprolactone produced using in situ polymerisation: A novel manufacturing technique for long-fibre composite materials. Biomaterials 21: 713-724, 2000.

29. Ambrose CG, Clyburn TA, Louden K, Joseph J, Wright J, Gulati P Gogola GR and Mikos AG: Effective treatment of osteomyelitis with biodegradable microspheres in a rabbit model. Clin Orthop Relat Res 421: 293-299,2004.

30. Mäkinen TJ, Veiranto M, Lankinen P, Moritz N, Jalava J, Törmälä P and Aro HT: In vitro and in vivo release of ciprofloxacin from osteoconductive bone defect filler. J Antimicrob Chemother 56: 1063-1068, 2005.

31. Stiller M, Kluk E, Bohner M, Lopez-Heredia MA, Muller-Mai C and Knabe C: Performance of $\beta$-tricalcium phosphate granules and putty, bone grafting materials after bilateral sinus floor augmentation in humans. Biomaterials 35: 3154-3163, 2014.
32. Yoshikawa T, Ohgushi H, Uemura T, Nakajima H, Ichijima K, Tamai $\mathrm{S}$ and Tateisi T: Human marrow cells-derived cultured bone in porous ceramics. Biomed Mater Eng 8: 311-320, 1998.

33. Hile DD, Amirpour ML, Akgerman A and Pishko MV: Active growth factor delivery from poly(D,L-lactide-co-glycolide) foams prepared in supercritical CO(2). J Control Release 66: $177-185,2000$.

34. Zhang YM, Li BX, Li J, Ma HQ, Zhao YP and Yuan L: Preparation of porous polylactic-acid/ bone matrix gelatin composite as scaffold materials for bone-tissue engineering. Nan Fang Yi Ke Da Xue Xue Bao 26: 1745-1748, 2006 (In Chinese).

35. Link DP, van den Dolder J, Jurgens WJ, Wolke JG and Jansen JA: Mechanical evaluation of implanted calcium phosphate cement incorporated with PLGA microparticles. Biomaterials 27: 4941-4947, 2006.

36. Yandrapu SK, Upadhyay AK, Petrash JM and Kompella UB: Nanoparticles in porous microparticles prepared by supercritical infusion and pressure quench technology for sustained delivery of bevacizumab. Mol Pharm 10: 4676-4686, 2013.

37. Nofar M, Tabatabaei A and Park CB: Effects of nano-/micro-sized additives on the crystallization behaviors of PLA and PLA/CO2 mixtures. Polymer 54: 2382-2391, 2013.

38. Li Z, Ramay HR, Hauch KD, Xiao D and Zhang M: Chitosan-alginate hybrid scaffolds for bone tissue engineering. Biomaterials 26: 3919-3928, 2005.

39. Bucholz RW: Nonallograft osteoconductive bone graft substitutes. Clin Orthop Relat Res 395: 44-52, 2002.

40. Porter NL, Pilliar RM and Grynpas MD: Fabrication of porous calcium polyphosphate implants by solid freeform fabrication: A study of processing parameters and in vitro degradation characteristics. J Biomed Mater Res 56: 504-515, 2001. 